\title{
Use of the pro-seal laryngeal mask airway facilitates percutaneous dilatational tracheostomy in an intensive care unit
}

\author{
Suman Sarkar, P Shashi ${ }^{1}$, Anil Kumar Paswan'1, R.P. Anupam¹, S. Suman², Surya Kumar Dube ${ }^{3}$
}

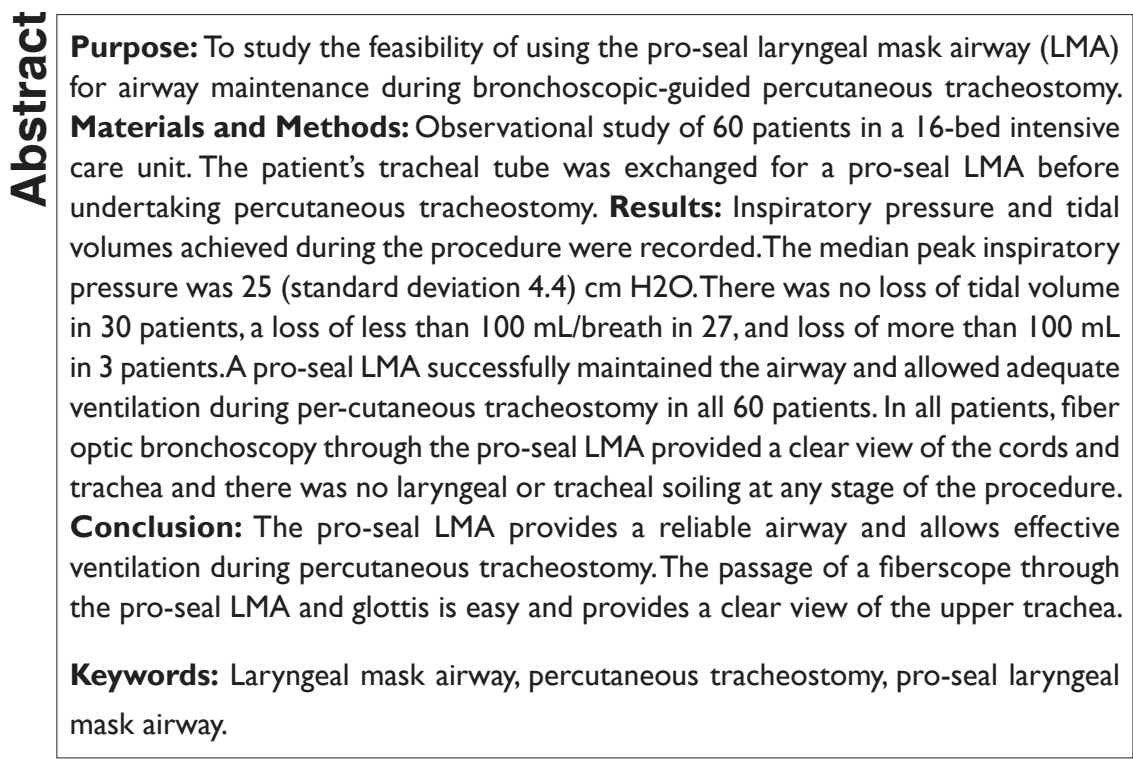

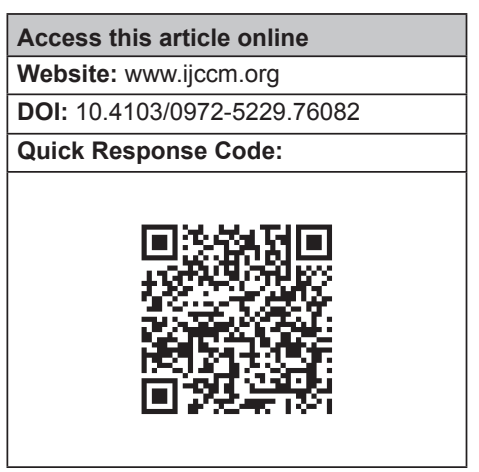

\section{Introduction}

Using percutaneous dilatational tracheostomy the patient's airway is usually maintained with an endotracheal tube, which is pulled back until the cuff is lying across the vocal cords. ${ }^{[1,2]}$ In this position, the tracheal tube is unstable and may become dislodged with loss of the airway and risk of aspiration. Most commonly, fiber

\section{From:}

Department of Anesthesiology, Institute of Post Graduation Medical Education and Research (I.P.G.M.E.R), Kolkata, West Bengal, India. 'Department of Anesthesiology, Institute of Medical Sciences, Banaras Hindu University, Varanasi, Uttar Pradesh, India. ${ }^{2}$ Department of Anesthesiology, Maulana Azad Medical College and Associated Lok Nayak and GB Panth Hospitals, New Delhi-110 002, India. ${ }^{3}$ Department of Anesthesiology, All India Institute of Medical Sciences (AlIMS), New Delhi, India

\section{Correspondence:}

Dr. Suman Sarkar, Department of Anesthesiology, Institute of Post Graduation Medical Education and Research (I.P.G.M.E.R), Kolkata, West Bengal, India.

E-mail: suman_nm@ rediffmail.com optic bronchoscopy is undertaken during the procedure to aid the correct placement of the guidewire. ${ }^{[3]} \mathrm{An}$ assistant is generally required to stabilize the tracheal tube while fiberoptic examination is performed and, as the glottis is not seen, it can be very difficult to determine the level at which the cannula enters the trachea. The tip of the tracheal tube may still lie low enough within the trachea to risk cuff puncture or tube transfixion by the needle or by the guide wire. ${ }^{[4]}$ Use of the classic laryngeal mask airway (LMA) ${ }^{[5-7]}$ or the intubating $\mathrm{LMA}^{[8]}$ during percutaneous dilatational tracheostomy (PDT) circumvents many of these problems. However, patients requiring PDT often have poorly compliant lungs requiring high inflation pressures. Gas leak from between the LMA and glottis increases as inspiratory airway pressure rises, particularly above $20 \mathrm{~cm} \mathrm{H}_{2} \mathrm{O}^{[9]}$ This leads to a risk of hypoventilation in patients with poorly compliant lungs. 


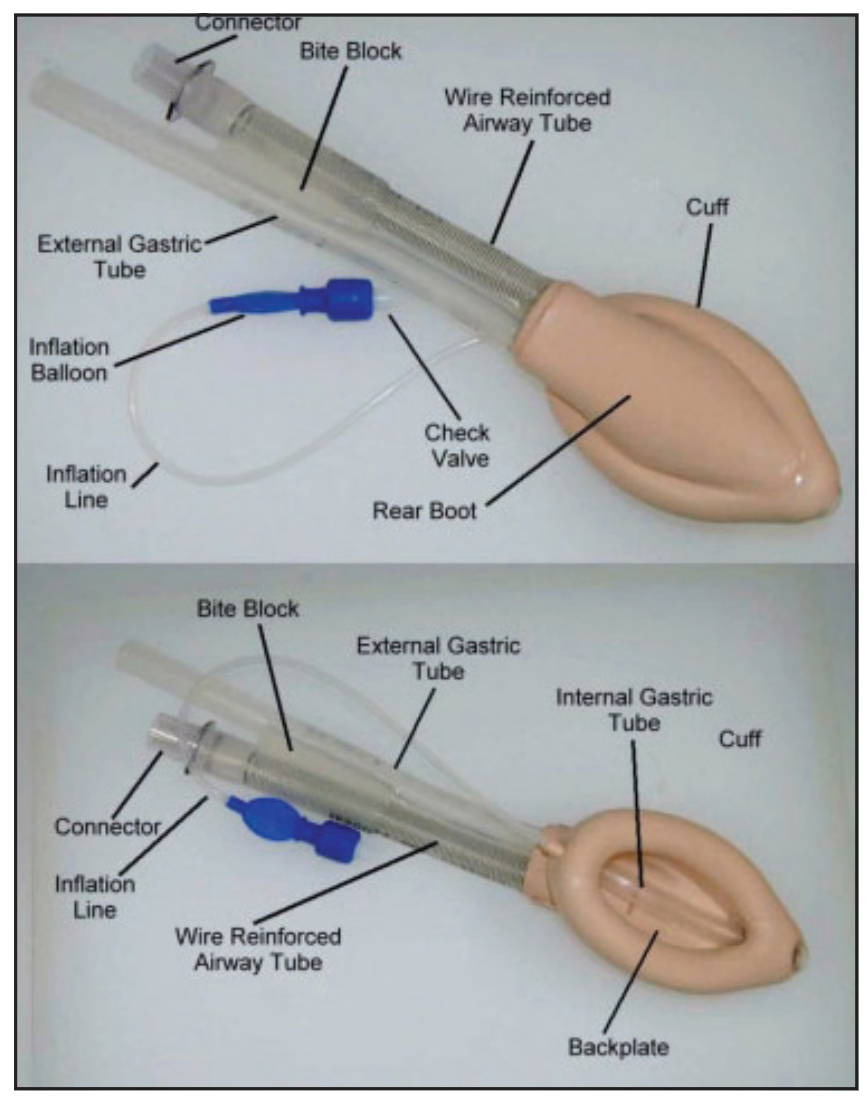

Figure I: Pro-seal laryngeal mask airway

Pro-seal LMA has a drain tube lateral to the airway tube and ending at the mask tip ${ }^{[10]}$ [Figure 1]. The second tube aids the correct placement of the mask; if the mask is placed correctly, with its tip against the upper esophageal sphincter, no air leak is heard. This tube allows the passage of a gastric tube and will vent air or fluid from the upper esophagus and stomach. The pro-seal LMA provides a better laryngeal seal than the classic LMA because of a deeper mask bowl and extension of the cuff over the posterior aspect of the bowl. ${ }^{[11]}$ The aim of this observational study was to evaluate the efficacy of the pro-seal LMA during PDT under bronchoscopic guidance.

\section{Materials and Methods}

\section{Patients}

We prospectively studied 60 consecutive patients in the intensive care unit who required elective tracheostomy. The lungs of all patients were ventilated with a PuritanBennett ventilator using a positive airway pressure mode. We excluded those patients who needed inspiratory pressure more than $40 \mathrm{mmHg}$ due to very bad lung pathology (pulmonary edema, collapse, ARDS, etc)

\section{Technique}

Before PDT, enteral feeding was withheld for $6 \mathrm{~h}$ in all patients and all of them were pre-medicated with metoclopramide i.v. as a prokinetic agent. All patients were sedated with propofol $100-200 \mu \mathrm{g} / \mathrm{kg} / \mathrm{min}$ and fentanyl 0.5--1 $\mu \mathrm{g} / \mathrm{kg} / \mathrm{h}$. Paralysis was achieved with vecuronium $0.1 \mathrm{mg} / \mathrm{kg}$. The inspired oxygen concentration was increased to $100 \%$. The pharynx was suctioned with a soft suction catheter. The nasogastric tube was aspirated and left in situ throughout the procedure. The patient was positioned with the neck extended and a pillow placed under the shoulders. A direct laryngoscopy done in all patients to assess the airways, after satisfactory findings, the tracheal tube was removed, a pro-seal LMA inserted (size 3 for females and size 4 for males), and the cuff inflated. Correct positioning of the pro-seal LMA was confirmed by the achievement of an adequate expired tidal volume with minimal leak from the drain tube and appearance of capnograph.

The patient's neck was cleaned and draped. The cricoid cartilage was identified and the skin over the space between the first and second tracheal rings was infiltrated with $2 \%$ lignocaine with adrenaline. A fiberoptic bronchoscope was passed through a swivel connector on the pro-seal LMA. The tip of the bronchoscope was positioned just below the glottis and correct position of the tracheal puncture was confirmed in relation to both the midline and the level. A Cook 'Blue Rhino' PDT kit was used in all cases. The airway pressure and tidal volumes were recorded during insertion of the dilator and the presence of any gas leak was noted.

\section{Results}

The pro-seal LMA successfully maintained the airway and allowed adequate ventilation during percutaneous tracheostomy in all 60 patients. In seven patients more than one attempt was required to insert the device. In five male patients the size 4 pro-seal LMA was changed to a size 5 and in three female patients the size 3 pro-seal LMA was changed to a size 4 to provide a better seal with the larynx. The median peak inspiratory pressure was 25 $\mathrm{cm} \mathrm{H}_{2} \mathrm{O}\left(\mathrm{SD} 4.4 \mathrm{~cm} \mathrm{H}_{2} \mathrm{O}\right.$ ) and the median expired tidal volume was $400 \mathrm{~mL}$ (SD $91 \mathrm{~mL}$ ). We have used Stela puda hozo et al, theory to detect SD from median. ${ }^{[12]}$ There was no loss of tidal volume in 30 patients, minimal loss (less than $100 \mathrm{~mL} /$ breath) in 27, and moderate loss (200 mL) in 3. The lowest $\mathrm{SpO}_{2}$ recorded during the procedure was $88 \%$ (due some difficulty to insert PLMA and it took more than one attempt). The median lowest recorded $\mathrm{SpO}_{2}$ was $94 \%$. Gastric fluid appeared in the drain tube during the procedure in six patients. In three of these cases this fluid was approximately $40 \mathrm{~mL}$ of enteral feeding solution (despite aspiration of the stomach before 
the procedure), and in the other it appeared to be bile. In these cases, the fluid was vented effectively up the drain tube. In all patients bronchoscopy through the pro-seal LMA provided a clear view of the cords and trachea and there was no laryngeal or tracheal soiling at any stage of the procedure.

\section{Discussion}

Use of any form of LMA during PDT has the potential to overcome many of the problems associated with the procedure. ${ }^{[5-8]}$ In particular, the airway device is in a stable position and lies outside the larynx minimizing the risks of dislodgement, glottic damage and tube transfixion. ${ }^{[4]}$ Fiber optic Bronchoscopic examination may be performed from the laryngeal inlet allowing accurate identification of the laryngeal rings and avoiding risk of damage to the bronchoscope. In comparison with the classic LMA, the absence of aperture bars on the pro-seal LMA improves bronchoscopic access to the glottis during the procedure. In the presence of poor lung compliance and high airway pressures, the proseal LMA will provide more effective ventilation than the classic $\mathrm{LMA}^{[10,11]}$ and it allows adequate ventilation in all 60 patients despite inspiratory airway pressures of up to $40 \mathrm{~cm} \mathrm{H}_{2} \mathrm{O}$.

Provisional work in cadavers, supported by some case reports, suggests that the drain tube of the pro-seal LMA will allow regurgitated matter to bypass the larynx..$^{[13-15]}$

This was witnessed in four of our patients and, in all patients, laryngeal/tracheal soiling was absent. The potential for airway loss during changeover of the airway device is a theoretical limitation of the technique. However, accidental extubation during PDT may also cause loss of the airway as well as the risk of aspiration.

\section{Conclusion}

Our experience suggests that the pro-seal LMA can be used to safely maintain the airway during PDT. Use of the pro-seal LMA during bronchoscopic-guided PDT facilitates a good view of the upper trachea and avoids the possibility of accidental extubation or puncture of the tracheal tube cuff.

\section{References}

1. Ciaglia P, Firsching R, Syniec C. Elective percutaneous dilatational tracheostomy: A new simple bedside procedure: Preliminary report. Chest 1985;87:715-9.

2. Mercer M, Manara AR. Percutaneous tracheostomy in the intensive care unit. Curr Opin Anaesthesiol 1999;12:701-6.

3. Reilly PM, Shapiro MB, Malcynski JT. Percutaneous dilatational tracheostomy under the microscope: justification for intra-procedural bronchoscop. Intensive Care Med 1999;25:3-4.

4. Channa AB, Hussain A, Nawaz S, Al-Kendi M. Inadvertent entry of a guide wire through the Murphy's eye causing difficulty in passing a percutaneous tracheostomy tube with seldinger technique: A case Report. Internet J Anesthesiol 1092-406X.

5. Dexter T.J. The laryngeal mask airway: A method to improve visualisation of the trachea and larynx during fibreoptic assisted percutaneous tracheostomy. Anaesth Intensive Care 1994;22:35-9.

6. Zuleika M, Jacobs S, Mphanza T, Brohi F. The use of the laryngeal mask airway in suitable ICU patients undergoing percutaneous dilational tracheostomy. Intensive Care Med 1997;23:129-30.

7. Dosemeci L, Yilmaz M, Gurpinar F, Ramazanoglu A. The use of the laryngeal mask airway as an alternative to the endotracheal tube during percutaneous dilatational tracheostomy. Intensive Care Med 2002;28:63-7.

8. Veghese C, Rangasami J, Kapila A, Parke T. Airway control during percutaneous dilatational tracheostomy: Pilot study with the intubating laryngeal mask airway. Br J Anaesth 1998;81:608-9.

9. Devitt JH, Wenstone R, Noel AG, O'Donnell MP. The laryngeal mask airway and positive-pressure ventilation. Anesthesiology 1994;80:550-5.

10. Brain AIJ, Verghese C, Strube PJ. The LMA 'Pro-Seal' a laryngeal mask with an oesophageal vent. Br J Anaesth 2000;84:650-4.

11. Cook TM, Nolan JP, Verghese C, Strube PJ, Lees M, Millar JM, et al. A randomized crossover comparison of the ProSeal with the classic laryngeal mask airway in unparalysed anaesthetized patients. Br J Anaesth 2002;88:527-33.

12. Hozo SP, Djulbegovic B, Hozo I. Estimating the mean and variance from the median, range, and the size of a sample. BMC Med Res Methodol 2005;5:13.

13. Keller C, Brimacombe J, Kleinsasser A, Loekinger A. Does the ProSeal laryngeal mask airway prevent aspiration of regurgitated fluid? Anesth Analg 2000;91:1017-20.

14. Evans NR, Llewellyn RL, Gardner SV, James MF. Aspiration prevented by the ProSeal ${ }^{\mathrm{TM}}$ laryngeal mask airway: a case report. Can J Anesth 2002;49:413-6.

15. Mark DA. Protection from aspiration with the LMA-ProSeal ${ }^{\mathrm{TM}}$ after vomiting: A case report. Can J Anesth 2003;50:78-80.

Source of Support: Nil, Conflict of Interest: None declared. 